June - 2007

\title{
Instant Messaging for Creating Interactive and Collaborative m-Learning Environments
}

\author{
James Kadirire \\ Anglia Ruskin University, England
}

\begin{abstract}
'Instant Messaging' (IM) and 'Presence,' which is essentially the ability of being able to detect if other users are logged in on the network and send them messages in real time, has become one of the most popular applications of the Internet, causing people to want to stay connected to the Internet for inordinate amounts of time, a phenomena that also fosters a sense of "online community," that perhaps no other application has done previously (Alvestrand, 2002). This research looks at the use of mobile devices to send instant messages that can carry much more information than the short message service (SMS) messages, but would be free to use, notwithstanding the price of getting online. We present a prototype IM system that can be used as a viable means of communicating and learning in higher education establishments. There is some evidence to show that learning using mobile devices reduces the formality of the learning experience, and helps engage reluctant learners and raise their self-confidence. In order for the learning process to be successful in online distance learning, unlike in the traditional face-to-face learning, attention must be paid to developing the participants' sense of community within their particular group. Instant messaging - or IM - is a natural medium for online community building and asynchronous/ synchronous peer discussions.
\end{abstract}

Keywords: Instant messaging; mobile device; wireless; presence; chat; authentication; database; microportal

\section{Introduction}

The introduction of the General Packet Radio Service (GPRS), Enhanced Data GSM Environment (EDGE), and Universal Mobile Telecommunications System (UMTS) /3G networks, has made it possible for users to browse the Web or hold videoconferences from mobile phones or portable digital assistants (PDAs). The potential offered by these developments is huge, particularly in education where not only the short message service (SMS), but also instant messaging (IM) can be used. Mobile devices have truly become ubiquitous and pervasive, with over two billion mobile users worldwide, sending 235 billion SMS messages in the first quarter of 2006 (Cellular Statistics, 2006). In the United Kingdom alone, there were 41.8 billion text or SMS messages in 2006, giving a daily SMS average for the year of 114 million (Text.IT, 2006). There is also evidence from a story published in Cellular Online (2003), which claims that there is a boom in the number of British citizens that are using GSM text or SMS messaging. Although SMS is quick and easy to use, it comes at a cost, not only in monetary terms, but also in the maximum number of characters that can be used for a message. 
'Instant Messaging' (IM) and 'Presence,' which is essentially the ability of being able to detect if other users are logged-in on the network and send them messages in real time, has become one of the most popular applications of the Internet. Instant messaging is making people want to stay connected to the Internet for an inordinate period of time, a phenomenon that is also helping to foster a greater sense of "online community" that no other application has done previously (Alvestrand, 2002). Instant messaging is becoming widespread in universities and is now being used for online discussions, chatting, file transfer, library access and usage, and so forth. Some of the most common IM applications are AOL Instant Messenger, MSN Messenger, Yahoo Messenger, Google Talk, and Skype. All IM systems support avatars (a movable icon representing a person in cyberspace or virtual reality graphics), in addition to user icons. Instant messaging has also become the latest employee productivity tool (Hinds \& Kiesler, 2002). For example, a customer-service representative can use it as a quick-and-easy way to answer an enquiry, whereas a salesperson can inform a busy vice president about a new account. Gartner (as cited in Korzeniowski, 2004) estimates that 70 per cent of corporate employees rely on IM while at work. According to the research conducted by Lenhart and Shiu (2004), 42 per cent of Internet users in the United States (about 53 million people) use instant messaging, and its appeal is apparent amongst young adults and technology enthusiasts. Research carried out at Wake Forest University (Walker, 2005) has shown that student mobile phone usage patterns are moving away from more traditional messaging, like email for instance, to newer technologies such as instant messaging and SMS. This trend should encourage students to become more engaged with course material outside the classroom, and help them communicate better among themselves. Often students want to communicate or locate other people while in indoor environments, for instance, in a meeting room, lecture theatre, or inside a large building; mobile phones and laptops are ideal devices for this.

Our research is also supported by the article published in NESTA FutureLab (2005), which claims that a mobile phone also increases the possibilities for informal learning that is not tied to a particular physical location. Students can stay in touch with their tutors and with each other while they are away from the classroom. It argues that mobile devices are being used quite comfortably for discussions and so a discussion that can be enriched with other media makes the phone an 'important collaborative learning tool.' Perhaps the most revolutionary aspect of mobile technology is that it addresses the problem of social inclusion. Many young people who would not go near a university or who do not own a computer, typically do own a mobile phone. A three year pan-European research project carried out at Anglia Ruskin University and its European partners into mobile learning (m-Learning) found that learning with mobile devices was good at reducing the formality of the learning experience, engaging reluctant learners, and raising selfconfidence (Attewell, 2004). The e-Viva research project at Anglia Ruskin Univeristy, funded by the Qualifications and Curriculum Authority, enabled its Key Stage 3 students (Key Stage 3 covers children aged 11-14 in years seven, eight, and nine at schools in England) to take part in assessments by answering pre-recorded questions over their mobile phones. This research showed that teachers believed that mobile phone usage made their pupils much more aware of what they were doing and why they were doing it. Knowing that their work was going to be seen by others also had a positive effect, in that it increased their motivation and built their self confidence (Walton, 2005). Research in mobile learning in classrooms by Roibas and Sanchez (2002) also showed that the way forward in mobile learning in formal educational settings, will be the introduction of handheld devices. Research carried out in the Numina project at the University of North Carolina at Wilmington (Vetter, Heath, Herman, et al., 2005) found that students enjoyed the technology and became more active in their learning when handheld pocket computers were used in the classroom. It also suggests that there is every indication that in the near future, wireless data devices will be as widespread as wireless voice devices are now. Experience with Anglia Ruskin University's fully online degree has shown that when students were asked to 
evaluate the effectiveness of their online learning experience, it was their ability to engage in asynchronous discussions with their peers that they valued the most (Ultralab, 2006). Unlike in face-to-face classroom settings, in order for the learning process to be successful in online distance education, attention must be paid to developing a sense of community amongst participants. Indeed, instant messaging is a natural medium for online community building and asynchronous peer discussions (Nardi, Whittaker, \& Bradner, 2000; Rheingold, 2000; QuanHaase, Cothrel, \& Wellmann, 2005).

This paper first looks at the design of an IM system used for the creation of interactive and collaborative m-Learning environments. It also looks at the use of mobile devices (mobile phones and PDAs) used to send instant messages that can carry more information than text or SMS messages, and are offered free of cost, except for the price of connecting online and downloading content. For instance, mobile telephone operators in the United Kingdom, charge GPRS/ 3G users based on the amount of the data downloaded in kilobytes. If the instant message arrives while the user is not online, it can be stored in a database; when the user logs on, he or she can retrieve their messages off the database, rather like email. With technologies such as Web-enabled and IEEE 802.11x enabled mobile phones and PDAs, connected to IEEE 802.11x networks (IEEE 802.11x is technical speak for Wireless Fidelity/ Wi-Fi hotspots) mobile wireless communications are well on their way to becoming pervasive. So, for those users whose mobile phones are Wi-Fi enabled, like the Nokia N80, Nokia N95 and the Sony Ericsson P990i that have fully working Web browsers for example, their usage costs will become less of an issue. These mobile devices allow users to connect to their campus networks, surf the Web, and take part in instant messaging sessions, typically for free. If they have subscribed to a broadband Internet connection, users can also logon to the Internet via their wireless hotspots at home, also free. Not only do these advancements arguably make online distance learning much more attractive, irrespective of where users are physically located, they also foster a greater sense of connectedness and community amongst users.

The next section on "System Design" looks at the instant message environment and what components an IM system must have. It also examines 'content adaptations,' specifically how one must adapt content that is normally designed for regular sized computer display screens, to fit onto small mobile, handheld devices (typically with a 200 x 300 pixel screen resolution). This section is followed by sections on the "System Architecture," "Mobile Devices Used," "Results," "Discussion and Conclusion" and suggested avenues to "Future Research."

\section{System Design: The instant message environment}

The system is essentially based on the idea of a community of students within some educational establishment. The instant message environment is composed of multiple features or components, some of which are:

- User identity - This identifies the valid user of the system and in our system, it is made up of the user name and password for authentication.

- User Profile/ Microportal - In all instant messaging systems, it is important for users within a particular online community to be able to find out basic information about the other users without having to ask anyone. It is important for registered and authenticated users to be able to look up any other registered users on the system and get details about them (i.e., their age, picture, interests, etc.). Such functionality is provided via a user profile or microportal, which is created dynamically when each user logs on. A 
Instant Messaging for Creating Interactive and Collaborative m-Learning Environments Kadirire

microportal is a small version of a portal and has essentially the same meaning as a portal. A portal is a Web-based application that commonly provides personalization, single entry point log-in, content aggregation from different sources, and hosts the presentation layer of information systems. Aggregation is the process of integrating content from different sources within one webpage (Kadirire, 2005a). For the purpose of our research, we define a microportal as a Web-based application that is essentially a simpler and smaller version of a portal, but specifically targeted at mobile devices. Also, from within their microportal, users can access learning content from a learning management system (see Figure 1).

- User Database or Directory - This is the main database that stores all the system users and has a list of those that are also currently logged in. In this research, we used an Oracle 9i database running on Windows 2000.

- Presence Awareness - This is the ability to determine if a user is logged on. We implement this by setting a flag in the database tables which was activated when a user logged-on and reset it when they log-off. So, it is only a matter of querying the database to display a list of the users currently logged-on. When users are logged-on to the system, they will appear on a contacts list of online users. From this list, it should be possible to invite selected users for a private synchronous chat or a one-on-one instant messaging session.

- Instant Messages - These have been implemented very much like email. Messages are stored in the database and if a user is logged-on, they will receive a notification by an unopened mail-message icon to alert them of the new instant message. They can reply to their instant message straight away or choose not to, if they wish.

- Asynchronous Chat - If a user is not online and another user knows their user identification/ name, they can send them an instant message, which will be stored on the database. The next time they login, they will be notified of an instant message they have waiting for them. This means that messages need never be missed; they can be received and handled both synchronously and asynchronously.

- Message Size - The size of the messages will be determined by the database used. This research uses Oracle $9 i$ for storing the messages and attributes associated with each user. Up to 4000 characters or bytes can be stored as text in each field, which means an instant message can be up to 4000 characters long, and which is 25 times longer than an SMS message.

- $\quad$ Ease of Use - The user interface must be graphical, user friendly, and easy to use.

- Multi-user Chat - In addition to providing one-to-one synchronous chat, IM systems should allow users in the community to chat in groups (which can be selected based on the names of the 'chat room' created by the administrator). We implemented a Web-based chat service, which students also used as part of their messaging to interact as a group if they so desired.

- $\quad$ Security - There is an authentication system which provides security for the users of the system. If the IM system is made an open system (i.e., anonymous users are able to join in) this poses serious security risks to online resources. This also opens the door to computer viruses being 'injected' into the IM system by potentially malicious users. 
Clearly, no online system can be 100 per cent secure. As such, one must assume that 'registered users' of the university who have gone through the the normal university selection, vetting, and registration processes, will have no malicious intent. The credentials used for authentication to the IM system will be the user name and password (after the user has had their student status verified).

\section{System Design: Content adaptation}

To be able to use instant messaging for m-Learning on mobile devices, the software must be intelligent and adaptable, and render well on different devices with widely varying capabilities. However, designing software for different mobile devices is often a resource allocation problem wherein the utility-value of the content presented is maximised, subject to constraints (Chua, Scott, \& Blanchfield, 2005; Kadirire, 2005a). The main constraints used by existing Web-content adaptation engines are display resolutions, for instance, display size, colour-depth, and ability to display certain types of Web objects such as Flash files, animated gifs, and MP3 files. Some considerations that must be taken into account when calculating the utility of the contents are:

- Informational Content - When items are being converted to less resource-intensive forms, often the information content of the items is reduced and therefore needs to be accounted for (Mohan, Smith, \& Li, 1999). A good example of this is that images can only be shrunk so far before they become useless (Scott, 2003).

- Cost - Mobile telephone operators in the United Kingdom charge GPRS/ 3G users on the amount of the data downloaded in kilobytes. Therefore, when adapting content to be displayed on mobile devices, costs need to be taken into account in terms of the number of embedded images and size.

- Design Metrics - These are measures relating to composition (i.e., word count, link count), formatting (i.e., emphasized text, positioning), and other general webpage characteristics (i.e., total bytes) (Ivory, Sinha, \& Hearst, 2000). The presentation of Webcontent, such as the amount of text emphasis and the number of colours used, must be considered in calculating the utility of the adapted content. Research carried out by Scott and Koh (2003) shows that mobile device (i.e., PDA) webpages have different design metrics as compared to personal computer (PC) webpages.

- Relevance - Determining if an item really needs to be included in a webpage is clearly subjective. Much depends on who is viewing it, and its 'relevance' is difficult to factor into the design. Some research done in this area using "click stream analysis" (Anderson, Domingos, \& Weld, 2001) to determine an items purpose. An item can be categorised as being used for navigation, advertisement, as content, or even decorative purposes (Paek \& Smith, 1998).

To make this IM system user friendly, intelligent, and adaptable, we based the design on the following criteria:

- Web Browser Type - Each Web-browser has a user agent vis-à-vis a Web browser type. When the user accesses the website, the first thing the software does is that it detects the user agent to determine what type of device it is. 
- Device Characteristics - Each device has its characteristics stored in a database for use by the software to adapt the content when a device logs onto the system. The main characteristics stored are: screen resolution, colour depth, Web browser type, whether or not the device uses a stylus for navigation, whether or not it has a keyboard or joy stick, if it supports dynamic content like flash movies, animated gifs, MP3 files, and so forth, and the amount of memory it has.

- Generic HTML Template - Each page on an IM system has a generic HTML/ XML template used to create that page dynamically. The page is not stored in a static form; when the user logs-on, their device type is detected and the relevant instant message page is then created on-the-fly using the stored device characteristics in the database.

This design methodology, coupled with the use of object oriented design techniques in Java, makes the IM system design extremely robust, intelligent, and extensible. Only one set of software is required to adapt the content for all devices. When a new device is introduced, the only things that need to be done are to add the new devices characteristics to the database and also add a few lines of code to detect the user agent.

\section{System Architecture}

Figure 1. An example of IM system architecture

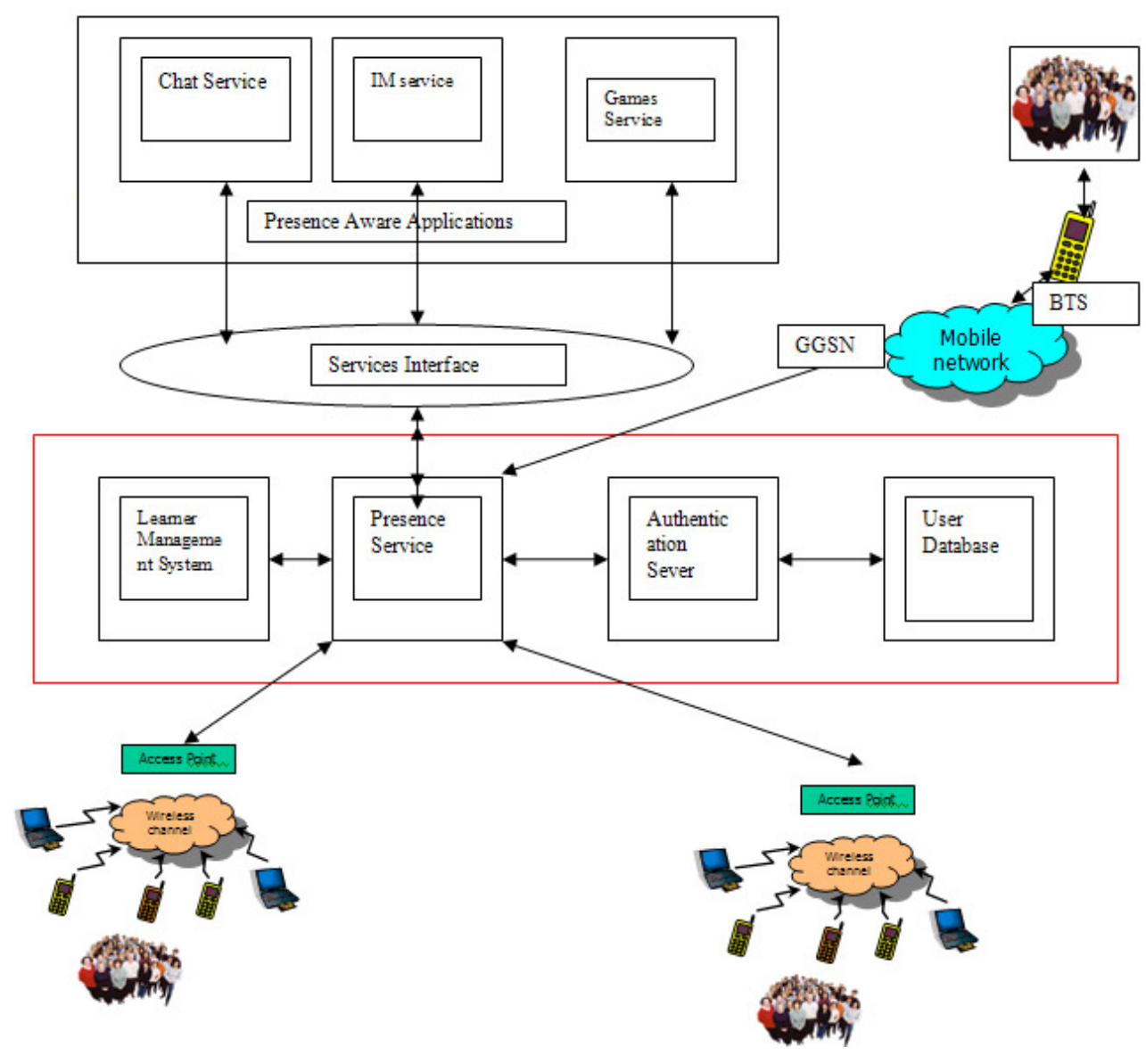


Figure 1 illustrates an example of system architecture. This system is made up of groups of students that may be connected to the Internet via mobile phones using the GSM/ GPRS/ UMTS network, or via Wi-Fi/ IEEE802.11x enabled mobile phones, such as the Nokia N80 for instance, or normal notebooks and laptops. The remainder of the system is comprised of a learning management system, an authentication server, user database, presence service, a services interface, and presence aware applications like the IM service, Chat service, and Games service. To deliver 'presence,' the system needs a network that can identify users independent of their location; this is done via the normal mobile telephone network (GSM/ GPRS/ UMTS) as well as the Wi-Fi wireless network users can access from their college campus, their home, or anywhere in the world where wireless access points, typically called 'hotspots,' are located. The database has all the registered user details for students who will be taking part in the online community via instant messaging.

\section{Mobile Devices Used}

The software was designed to detect and adapt the content for the devices listed below, which were in widespread use and were likely to continue being in widespread use. Because users in the UK have access to and use many types of mobile devices, we examined devices with different operating systems, functional capabilities, screen sizes and resolution, to make them more generic:

- Nokia Communicator 9210, running EPOC32 with an STNC-WTL/6.0 Web Browser. User-Agent: EPOC32-WTL/2.2 Crystal/6.0 STNC-WTL/6.0(611). Screen Resolution: 600x200 pixels

- Handspring TREO 270, running Palm OS 3.x with Blazer 1.o Web browser. UserAgent: UPG1 UP/4.0 (compatible; Blazer 1.0). Screen Resolution: 160x160 pixels

- SPV Orange Smart Phone, running windows CE with Internet Explorer 3.02. User-Agent: Mozilla/2.0 (compatible; MSIE 3.02; Windows CE; Smartphone; 176x220). Screen Resolution: 176x220

- 02 XDA PDA, running Microsoft Pocket PC 2002. User-Agent: Mozilla/2.0 (compatible; MSIE 3.02; Windows CE; PPC; 240x320). Screen Resolution: 240x320 pixels

- Sony Ericsson P800, running Symbian OS. User-Agent: Mozilla/4.1 (compatible; MSIE 5.0; Symbian OS) Opera 6.02 [en]. Screen Resolution: 175x320 pixels.

\section{Results}

Several user accounts were created at Ultralab, Anglia Ruskin University, to test access to the site. Results were positive. The criteria used to evaluate the IM system included: the speed of loading a webpage; the ease of navigating within the microportal; and the ease with which text could be typed into the chat or instant messenger windows. The user accounts were stored in the Oracle 9i database to test the IM system using the various mobile devices outlined above. A mobile device was detected during authentication by the authentication server, in conjunction with the user database, and stored in a session object. Figure 2a below shows the login interface when a user with a mobile phone like the Sony Ericsson P800 attempted to access the system. After they were authenticated, they were taken to their microportal or user profile as is shown in 
Figure $2 \mathrm{~b}$, where the user was authenticated and gained access using an $O 2 X D A P D A$ / mobile phone. The microportal was created dynamically by reading their data from the database and filling in some generic template using a servlet.

Figure 2a, a snapshot of the user login screen on the P800. Figure $\mathbf{2 b}$, an example of what the user sees when they first login.

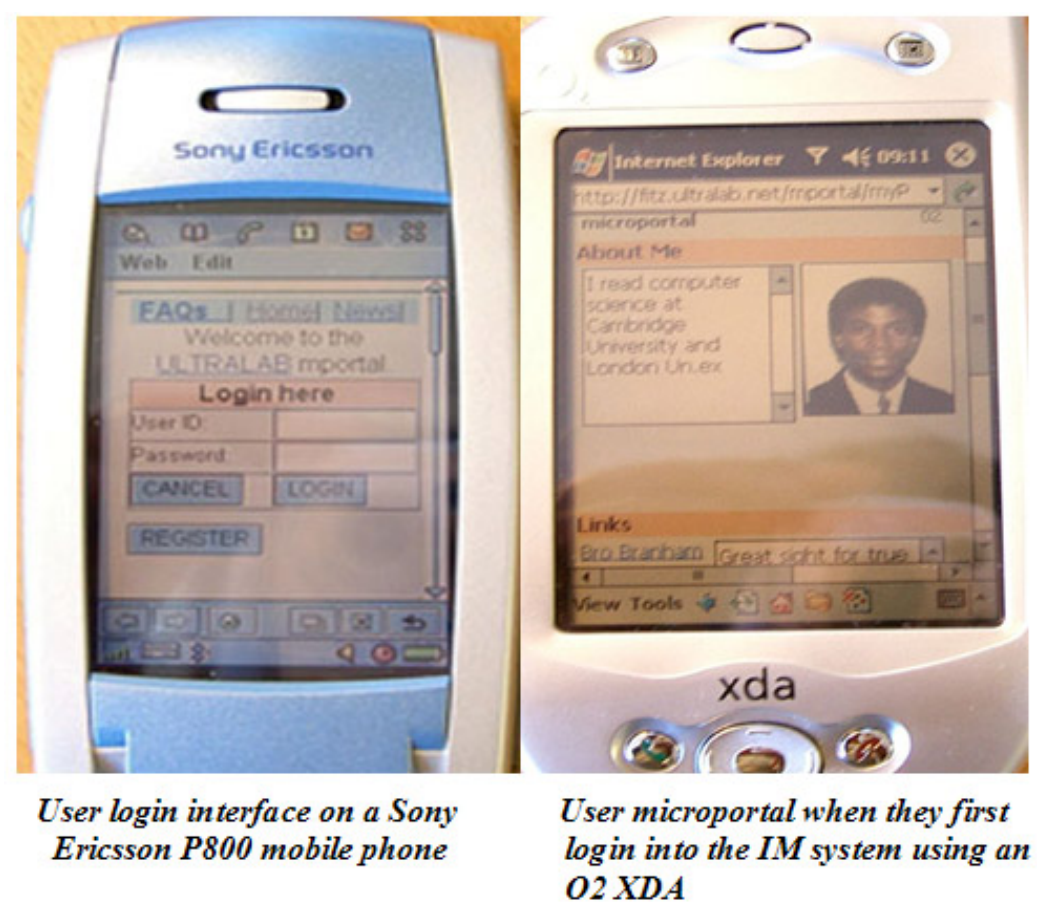

The software was designed in an adaptable and intelligent way, which allowed it to detect various types of mobile devices accessing the IM server and to format or adapt the content to fit the particular device capabilities. Mobile devices have different screen resolutions. Some have browsers and some do not. Some are in colour and some not. Some offer a stylus, while others do not offer that capability. We confined our research to mobile devices that had Web browsers only, as this made content adaptation more consistent and easier to implement. When a user logged in, they were automatically added to a list of users that could be sent an instant message. From within the users microportal, by clicking a link for the users that were online, a list of all the logged-in users could be displayed. By selecting a user from the list, a message could be composed and sent to that user. Figure 3a below shows how the instant message was composed. Figure $3 \mathrm{~b}$ shows what the user inbox looked like when they had messages waiting. There were essentially two ways of sending instant messages. The first method is as shown in Figure 3a, where the message was composed in a similar way to ordinary email. The second method was where a chat window was displayed and the users could type in messages in real time to each other. 
Figure 3a, a snapshot of an empty instant message screen. Figure 3b, a snapshot of a user's inbox showing instant messages received

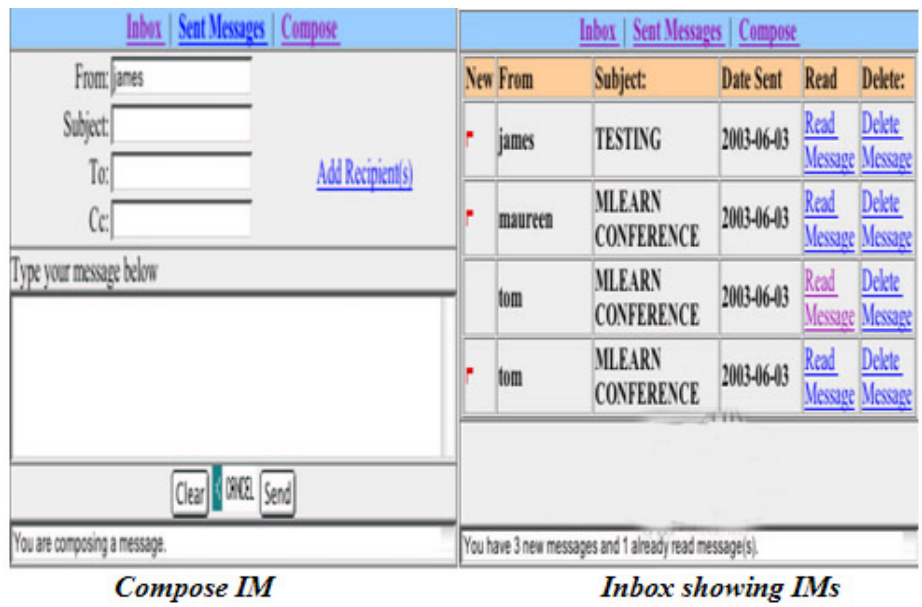

When a user first logged in, they were taken to their microportal, which among other things, has a message notifying them that they had messages waiting in their inbox. This could be either a text notification or a graphical notification such as icons representing unopened messages on the bottom part of the users microportal. Figure 3b shows the users inbox containing four messages, three of which had not been read (as denoted by the small red flags). To read an instant message, users click on the "Read Message" link for the particular instant message and which was then displayed, as shown in Figure 4a which shows an $\mathrm{O} 2 \mathrm{XDA}$ mobile phone was being used to read an instant message. In addition to reading instant messages, they could also be forwarded, as shown in Figure 4b. 'User identifiers' or names can also be called-up by pressing the "Add Recipient(s)" link, also shown in Figure 4b.

Figure 4a, a snapshot of an instant message displayed on the screen. Figure $\mathbf{4 b}$, a snapshot of an instant message being forwarded to another user.

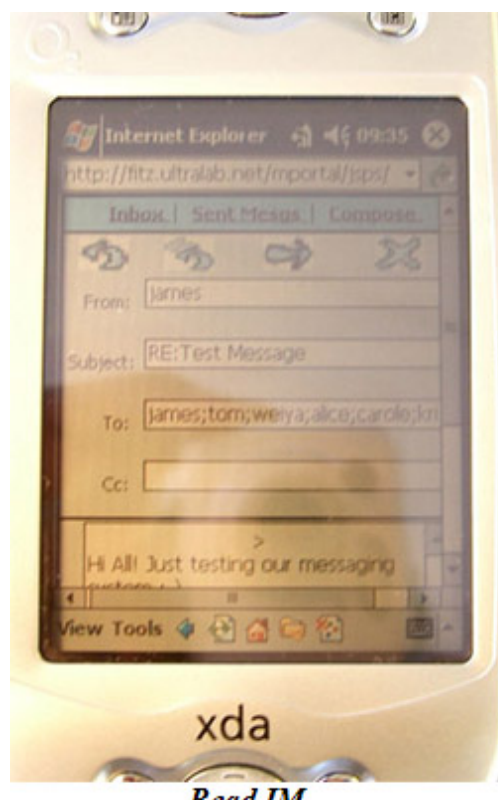

Read IM

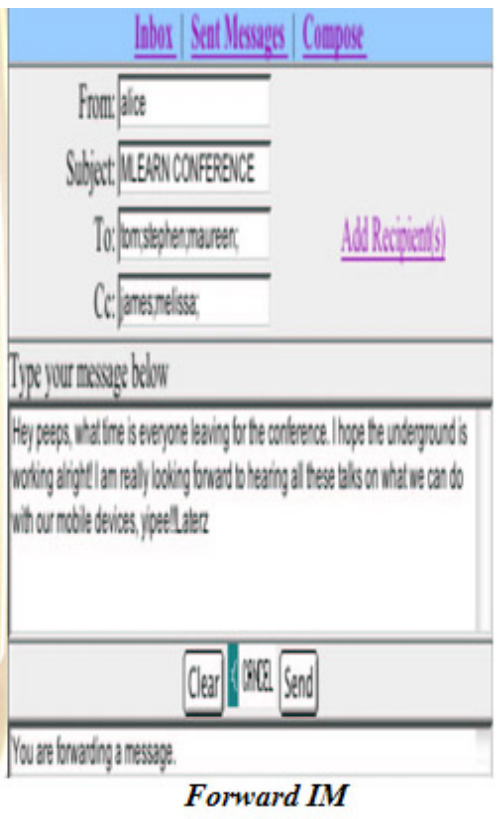


In addition to the instant messaging service, users also had access to learning material provided via the learning management system, accessed via the services interface on the microportal.

\section{Discussion and Conclusions}

Device characteristics like the resolution, Web browser type, et cetera, were stored in a database to allow rapid creation of the microportal from the same code and not have different software for each device. So, if a new device was introduced, there would be minimal changes to the code. This is one of the advantages of using Java as it is an object oriented language and is extensible and easy to modify.

No empirical data was collected in assessing the performance of the different mobile devices. Clearly, this is an area where things might have been done better. We instead relied on feedback from a group of about 10 users we specifically selected to help us evaluate the performance of the IM system. These 10 users were from within the Faculty and had an interest in using mobile device features like chatting and instant messaging. In terms of the speed with which the webpages were loaded, there did not seem to be any appreciable difference after logging into the IM system. However, the Windows-based devices, such as the $\mathrm{O} 2 \mathrm{XDA}$ and the SPV Orange Smart phones, did take longer in establishing a connection to the IM server. In terms of 'navigating content' and 'text entry' in the instant message chat window, two mobile devices with styluses, the Sony Ericsson P800 and the O2 XDA, in that order, were easier to use. Although the Handspring Treo 270 also has a stylus, it was awkward to use due to its inability to render images properly and its low resolution. The Nokia Communicator 9210 was the next best device in terms of 'content navigation' and 'text entry,' followed by the SPV Orange Smartphone, neither of which have a stylus. The best overall device for 'accessing content' and instant message text entry usage was the Sony Ericsson P800, followed by the O2 XDA. The Nokia Communicator also performed well, but its weight and size made it more like a laptop rather than a mobile device (although it is a mobile phone). The most awkward device to use was the SPV Smart phone, primarily because it lacked a stylus and its small keypad was found to be awkward for navigation and text entry. While there are many IM systems like MSN Messenger and Yahoo Messenger widely used already, we have shown how an IM system can be further designed for use in m-Learning environments that require enhanced interaction and collaboration.

Research carried out at Wake Forest University (Walker, 2005) shows that student mobile phone usage patterns are moving away from more traditional messaging like the use of email towards newer technologies such as IM and SMS. We feel this trend should encourage students to be more engaged with course material outside the classroom as well as communicate better among themselves. Limited research carried out by Sotillo (2006), for example, shows evidence of successful learner uptake in a synchronous instant messaging environment. The IM system presented in this research, which was part of a pan-European mobile learning research project (Attewell, 2004), shows that learners were typically enthusiastic about mobile learning, with 62 per cent reporting that they were keen to take part in future learning after trying mobile learning (which included instant messaging, as well as accessing online learning material via their mobile devices). Research by McGuire and colleagues with mobile devices (as cited in Walton, 2005) also showed that learning with mobile devices helped reduce the formality of the learning experience by engaging reluctant learners by raising self-confidence. In order for the learning process to be successful, attention must be paid to developing a strong sense of community in online distance education settings (Quan-Haase, et al., 2005). Not only does the quality of instant messages create a sense of connectedness and help bring people together, it is a natural medium for online community building and asynchronous peer discussions (Nardi, et al., 2000; Rheingold, 
2000). With technologies such as Web-enabled and IEEE 802.11x enabled mobile phones and personal digital assistants, IEEE 802.11x networks, mobile wireless communication is well on its way to becoming wholly pervasive. For mobile phone users with Wi-Fi enabled devices like the Nokia N80, Nokia N95 and the Sony Ericsson P990i, connection and usage costs are low simply because users can connect to their campus networks, surf the Web, and take part in instant message sessions, all for free. Mobile phone users with access to broadband connections can also access the Internet with their mobile devices via their wireless connections, which will not cost anything except for the basic cost of broadband access. Arguably, such trends will likely make online distance learning much more attractive, as they will bridge 'distance' between students and instructors. Users will only be aware of their particular online community, irrespective of where they are physically located. And while no single technology is going to create a complete collaborative learning environment, based on our own limited research, and research carried out by others (Sotillo, 2006), we believe that IM systems can play an important role in creating interactive and collaborative m-Learning environments. For instance, the research carried out by Sotillo (2006) shows that when corrective feedback was embedded in learning activities conducted via instant messaging tools (like the ones described in our research), learners were able to expand their linguistic competence outside the traditional face-to-face environment.

\section{Future Research}

\section{Collaborative filtering}

The growth of Internet commerce has stimulated the use of collaborative filtering (CF) algorithms as recommender systems. Collaborative filtering combines the informed opinions of humans to make personalized and accurate predictions, and recommend items of interest to other users. CF methods have been harnessed to make recommendations to users about such items as which webpages to browse, movies that might be of interest, relevant books to read, and toys to use, etc. Content-based filtering uses the speed of computers to make complete, fast predictions. Very little research, however, has been done on CF in education. As a follow-up from our instant messaging research, we propose to use CF in mobile settings. For example, if a student is, say, conducting research on a given subject, that student can be presented with a list of books or other relevant online resource materials (i.e., presentations, portals and communities of practice, online libraries, etc.). If a user queries information about, say, a particular sport at their university or school, they would also receive a list of recommendations on other collateral activities such as 'the best nearby restaurants to eat at' and information that other users found useful in this 'sporting' context. If a user queries information on where to find good material on, say, writing an essay on a particular subject, they can see what other resources students also found useful. The scope of CF is enormous, and we feel CF will influence how students/ pupils get information online using mobile devices. More significantly, CF will also allow the lecturer to focus on students' learning processes and progress, instead of on relaying facts or information such as administrative details.

\section{Acknowledgment}

This research was partly funded by the European Commission, under the Education Area of the Information Society (IST) Programme and co-ordinated by the Learning and Skills Development Agency. 
Instant Messaging for Creating Interactive and Collaborative m-Learning Environments

Kadirire

\section{References}

Alvestrand, H. (2002). Instant Messaging and Presence on the Internet. Brief published on the Internet Society.org website. Retrieved July 14, 2006 from:

http://www.isoc.org/briefings/009/briefing09.pdf

Anderson, C. R., Domingos, P., \& Weld, D. S. (2001). Personalizing web sites for mobile users. Proceedings of ACM 2001: 10th International WWW Conference. November 5-10. Atlanta Georgia, pp. 565-575.

Attewell, J. (2004). Mobile Technologies and Learning. Paper published on the Learning and Skills Development Agency website. Retrieved June 27, 2006 from:

http://www.Isda.org.uk/files/pdf/041923RS.pdf

Cellular Online (2003, December 20). UK GSM text messaging numbers boom. Retrieved June 27, 2006 from: http://www.mobileoffice.co.za/news 2003/121903uk gsm text messaging numbers bo.htm

Cellular Statistics (2006). Latest Mobile, GSM, Global, Handset, Base Station, \& Regional Cellular Statistics for April 2006. Retrieved June 27, 2006 from: http://www.cellular.co.za/stats/stats-main.htm

Chua, N. H., Scott, S. D., \& Blanchfield, P. (2005). Web-Page Adaptation Framework for PC \& Mobile Device Collaboration. AINA '05: 19th International Conference on Advanced Information Networking and Applications. March 28 - 30. Taipei, Taiwan. Retrieved April 24, 2007 from:

http://csdl2.computer.org/persagen/DLAbsToc.jsp?resourcePath=/dl/proceedings/\&toc $=\mathrm{c}$ omp/proceedings/aina/2005/2249/02/2249toc.xml

Ivory, M. Y., Sinha, R. R., \& Hearst, M. A. (2000). Preliminary findings on using quantitative measures to compare favourably ranked and unranked information-centric web pages. Paper presented at the 6th Conference on Human Factors and the Web. June 19, Austin, TX.

Hinds, P., \& Kiesler, S. (2002). Distributed work. Cambridge, MA.: The MIT Press.

Kadirire, J. (2005a). Learning with Mobile Devices - A Microportal Design Experience, Recent Research Developments in Learning Technologies. Paper presented at the Third International Conference on Multi-media and Technologies in Education. June 7-10, Cceres Spain. Retrieved June 27, 2006 from: http://www.formatex.org/micte2005/7.pdf

Kadirire, J. (2005b). The Short Message Service (SMS) for Schools/ Conferences: Recent research developments in learning technologies. Paper presented at the Third International Conference on Multi-media and Technologies in Education. June 7-10, Cceres Spain. Retrieved June 27, 2006 from: http://www.formatex.org/micte2005/4.pdf

Korzeniowski, P. (2004, March 31). Instant Messaging Opens New Security Holes. Published in TechNewsWorld.com. Retrieved June 27, 2006 from: http://www.technewsworld.com/story/33271.html 
Lenhart, A., \& Shiu, L. (2004). How Americans use instant messaging. Taylor University, archived Blog posting. Retrieved June 27, 2006 from: http://www.taylor.edu/Weblogs/zblog/archives/2004/09/new_report_on_h.html

Mohan, R., Smith, J. R., \& Li, C. S. (1999). Adapting multimedia Internet content for universal access. IEEE Transactions on Multimedia 1(1), 104-114. Retrieved July 14, 2006 from: http://ieeexplore.ieee.org/iel4/6046/16151/00748175.pdf?arnumber $=748175$

Nardi, B. A., Whittaker, S., \& Bradner, E. (2000). Interaction and Outeraction: Instant messaging in action. Proceedings of 2000 Conference on Computer Supported Cooperative Work (CSCW) December 2-6. (pp. 79-88). Philadelphia, PA.: ACM, Inc.

NESTA FutureLab (2005, June) The Future of Mobile Technology: Learning on the run? Retrieved June 27, 2006 from: http://www.nestafuturelab.org/viewpoint/vision/vision_01_04.htm

Paek, S., \& Smith, J. R. (1998). Detecting image purpose in World-Wide Web documents. From the proceedings of the IS\&T/ SPIE Symposium on Electronic Imaging: Science and Technology Document Recognition. January 21-26, San Jose, CA.

Quan-Haase, A., Cothrel, J., \& Wellmann, B. (2005). Instant Messaging for Collaboration: A case study of a high-tech firm. Journal of Computer-Mediated Communication, 10(4), 120 121

Sotillo, S. M. (2006). Using Instant Messaging for Collaborative Learning: A Case Study. Innovate, 2(3). Retrieved December 12, 2006 from: http://www.innovateonline.info/index.php?view=article\&id=170

Rheingold, H. (2000). The Virtual Community: Homesteading on the Electronic Frontier. Cambridge, MA.: MIT Press.

Roibas, A. C., \& Sanchez, I. A. (2002). Pathway to m-learning, Mlearn 2002. Proceedings of the European Workshop on Mobile and Contextual Learning. June, 20-21. Birmingham, UK.

Scott, S. D., \& Koh, Y. H. (2003). Design metrics and the adaptation of Web-page content chunks for PDAs. Proceedings of the 3rd International Conference on Information Technology in Asia, July 10-12, Kuching, Sarawak, Malaysia.

Scott, S. D. (2003). Edge-based algorithms for determining how far an image can be shrunk. Proceedings of ROSVISP 2003, The IEEE International Conference on Robotics, Vision, Information and Signal Processing, January 22-24. Penang, Malaysia.

Text.IT (2006, June 27). UK text messaging love affair surges ahead. Retrieved June 27, 2006, from http://www.text.it/home.cfm

Ultralab (2006). BA (Hons) Learning, Technology and Research program, part of the Ultraversity scheme run by Ultralab at Anglia Ruskin University. Retrieved June 27, 2006 from: http://www.ultraversity.net 
Vetter, R., Heath, B., Herman, R., Lugo, G., Reeves, J., \& Ward, C. R. (2005). Developing a mobile learning environment to Support Virtual Education Communities. PowerPoint presentation published on Dr. Ron Vetter's homepage at the University of University of North Carolina, Willimington. Retrieved June 27, 2006 from:

http://people.uncw.edu/vetterr/ncsu-mle-2005.ppt

Walker, C. (2005). WFU first with campus pilot of pocket PC phones. Wakeforest University News. Retrieved June 27, 2006 from: http://www.wfu.edu/wfunews/2005/082405m.html

Walton, S. (2005). The eVIVA project: Using e-portfolios in the classroom. Qualifications and Curriculum Authority website. Retrieved June 27, 2006, from http://www.qca.org.uk/10359.html

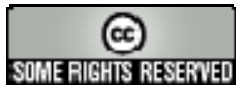

